\title{
A ATUAÇÃO DO PEDAGOGO NA EDUCAÇÃO NÃO-FORMAL: QUAIS POSSIBILIDADES DE INTERVENÇÃO PROFISSIONAL?
}

\section{THE ROLE OF EDUCATOR IN NON-FORMAL EDUCATION: WHICH PROFESSIONAL INTERVENTION POSSIBILITIES?}

\author{
Vanessa Silva Santos (PM/ISA) ${ }^{1}$ \\ Valdeci Luiz Fontoura dos Santos (UFMS) ${ }^{2}$
}

\begin{abstract}
Resumo: Este resumo socializa os resultados de uma pesquisa bibliográfica que teve como objeto a atuação do pedagogo nos espaços de educação não-formal. Fizemos um recorte da produção acadêmica sobre a formação do pedagogo e as possibilidades de uma atuação profissional em espaços de educação não-formal. Tendo como objetivo principal discutir a formação do pedagogo e o processo de sua atuação na educação não-formal, nos foi possível perceber que os egressos dos cursos de Pedagogia não são apenas docentes. A bibliografia encontrada aponta fortes posições que consideram o pedagogo como um profissional não restrito aos ambientes escolares e que suas ações pedagógicas estão presentes em toda a nossa sociedade: na família, nos meios de comunicação, hospitais, empresas, portanto em todos os espaços de nossa sociedade.
\end{abstract}

Palavras-chave: Pedagogos. Formação do Pedagogo. Pedagogia Social.

Abstract: This abstract socializes the results of a bibliographical research that aimed at the action of the pedagogue in the non-formal education spaces. We have scrutinized the academic production about the pedagogue formation and the possibilities of a professional action in non-formal education places. By discussing the pedagogue formation and his/her action in the non-formal education, we could realize that the Education courses egresses are not only teachers. The bibliography found points at strong positions that consider the pedagogue as a professional who is not restricted to the school environments, and that can dedicate to other pedagogical actions. They are inserted in our society: in the family, means of communication, hospitals, companies, thus in all positions of our society.

Key-words: Pedagogues. Pedagogue formation. Social pedagogy

\section{INTRODUÇÃO}

\begin{abstract}
A Educação é um dos requisitos fundamentais para que os indivíduos tenham acesso ao conjunto de bens e serviços disponíveis na sociedade. Ela é um direito de todo ser humano como condição necessária para ele usufruir de outros direitos constituídos numa sociedade democrática. (GADOTTI, 2005, p. 1).
\end{abstract}

Este artigo tem como intenção defender as possibilidades de intervenção profissional do pedagogo na educação não-formal. Para tanto, discutimos contribuições significativas para a atuação do pedagogo e sobre sua formação profissional fora do espaço-escolar. Assumiu-se o aporte metodológico da pesquisa bibliográfica, procedendo-se o levantamento bibliográfico

\footnotetext{
${ }^{1}$ Pedagoga vinculada ao Programa de Saúde da Família do Município de Ilha Solteira.

${ }^{2}$ Professor Assistente da Universidade Federal de Mato Grosso do Sul - UFMS.
}

\begin{tabular}{|l|l|l|l|l|l|}
\hline Interfaces da Educ. & Paranaíba & v. 2 & n. 5 & p.99-109 & 2011 \\
\hline
\end{tabular}


com livros de José Carlos Libâneo (2000); Selma Garrido Pimenta (1995); Emília Freitas de Lima (2004); Maria Amélia Santoro, dissertação de Maria Derise Fireman (2006), tese de Lourdes Maria Bragagnolo Frison (2006) e um artigo de Moacir Gadotti (2005).

De tal estudo, pôde-se ver o curso de Pedagogia além da docência o que representa um desafio para muitos profissionais da educação. Há quase 20 anos, a Associação Nacional pela Formação dos Profissionais da Educação (ANFOPE) lidera o movimento de reformulação dos cursos de formação dos profissionais da educação, defende um curso baseado na docência como base na formação pedagógica.

O que define um trabalho como sendo pedagógico? De acordo com Libâneo (2000)

[...] a Pedagogia ocupa-se da educação intencional. Como tal, investiga os fatores que contribuem para a construção do ser humano como membro de uma determinada sociedade, e os processos e meios dessa formação. Os resultados obtidos dessa investigação servem de orientação da ação educativa, determinam princípios e formas de atuação, ou seja, dão uma direção de sentido à atividade de educar. (LIBÂNEO, 2000, p. 25).

O pedagogo tem se caracterizado como o profissional responsável em direcionar as práticas de intervenção na Educação Não-Formal, já que sua formação permite um conhecimento amplo sobre o ato de educar. O trabalho pedagógico fora dos ambientes escolares traz uma inovação na atuação do pedagogo permitindo perspectiva na construção dos valores da cooperação, da solidariedade e da emancipação humana. Segundo Fireman (2006),

[...] nas atividades não-escolares ele pode atuar como: formador, animador, instrutor, organizador, técnico, consultor e orientador de atividades pedagógicas nãoescolares, e ainda como formadores ocasionais que estão ligados a atividades de transmissão de saberes e técnicas a outras atividades especializadas. (FIREMAN, 2006, p. 66).

\section{HISTORICIDADE DO CURSO DE PEDAGOGIA NO BRASIL}

Segundo Libâneo (2000), o curso de Pedagogia nasce no ano de 1939, na Faculdade Nacional de Filosofia, da Universidade do Brasil, o curso era composto de dois momentos, configurando o conhecido "esquema $3+1$ " - o primeiro momento com duração de três anos formava o Bacharel. O segundo, com um ano de estudos didáticos, formava o Licenciado.

No entanto, com o parecer $n^{\circ}$. 251/62, criado por Valnir Chagas, membro do Conselho Federal de Educação, considerou-se o curso de Pedagogia inadequado, pois the faltava conteúdos e não existia uma identidade própria. A proposta desse parecer era formar profissionais docentes em curso de graduação, e o bacharel especialista em curso de pósgraduação.

A Reforma Universitária é aprovada em 1968, por meio da Lei 5540, que tinha como uma das suas intenções reformular o curso Superior. Após essa reforma, o Parecer 251/62 é substituído pelo Parecer 252/62 e pela a Resolução $n^{\circ}$. 2 - oportunidade em que o aluno optava, em determinado ponto do currículo, tornando especialista em diversas áreas. Segundo Lima (2004),

O curso de Pedagogia era organizado, em ambas as fases, de forma conteúdista e fragmentária. Na primeira fase, separava-se Bacharelado e Licenciatura, e na segunda fragmentava-se a realidade escolar segundo as funções a serem 
desempenhadas: docência, administração, supervisão, orientação educacional, inspeção escolar entre outras. (LIMA, 2004, p. 17).

Na década de 1990, o Movimento para reformulação do curso de Pedagogia era uma preocupação constante nas discussões, sobretudo, quanto à identidade do curso de Pedagogia, sua função e estruturação. Com isso, houve a promulgação da Lei de Diretrizes e Base (LDB) $n^{\circ}$. 9394/96, o contexto que caracteriza o surgimento da lei inclui a substituição da concepção de conhecimento científico como nacional e imutável pela visão do ser humano como responsável pela construção do conhecimento e interação com o ambiente. Essas mudanças estão ligadas com a realidade da época referentes ao papel da escola e à concepção de conhecimento escolar, demanda das classes populares, médias e altas exigindo um novo projeto que atenda as diferentes vidas e supere as desigualdades sociais.

Com esses acontecimentos, se fez necessário uma nova visão escolar, em que priorizasse a cidadania, um ser democrático, social, solidário, intercultural e ambiental. Com isso, a escola não pode ser vista como uma instituição reduzida ao domínio dos conteúdos das disciplinas e à técnica para transmiti-los, exige-se que o professor lide com o conhecimento em construção. Nas palavras de Lima (2004 p, 18), é preciso "[...] que analise a educação como um compromisso político, carregado de valores éticos e morais, que considere o desenvolvimento da pessoa e a colaboração entre iguais e que seja capaz de conviver com a mudança e com a incerteza."

Com a promulgação da LDB 9394/96, no Título I, que se refere à Educação

Art. $1^{\circ}$. A educação abrange os processos formativos que se desenvolvem na vida familiar, na convivência humana, no trabalho, nas instituições de ensino e pesquisa, nos movimentos sociais e organizações da sociedade civil e nas manifestações culturais. (Lei de Diretrizes e Base no 9394, de 20 de dezembro de 1996).

A Educação na forma de Lei é bem objetiva ao se referir que ela vai além da instituição escolar, e que ela se encontra em qualquer lugar, onde se faz necessárias ações educativas. A LDB Art. 64 diz que também, será no curso de Pedagogia ou em pósgraduação, que se dará a formação de profissionais para atuar na administração, planejamento, inspeção e orientação na Educação Básica. As Diretrizes do Conselho Nacional de Educação de maio de 2006 diz que o curso de Pedagogia, assegura que essa formação não será uma habilitação, mas área do conhecimento que possibilitará ao egresso desse curso atuar como gestor, inspetor e orientador, e que, por sua vez, essa formação está acessível a todos os licenciados.

\section{DEFINIÇÕES DE PEDAGOGIA}

Nota-se com a história do Curso de Pedagogia, uma disputa de projetos uma crise de identidade. Afinal, surge o questionamento, Pedagogia é apenas para Licenciatura? Ou pode formar profissionais para a Educação Não-Formal?

O dicionário Aurélio (2004) define Pedagogia como

1. Teoria e Ciência da educação e do ensino; 2 . O conjunto de doutrinas, princípios e métodos de educação e instrução que tendem a um objetivo prático; 3 . O estudo dos ideais de educação, segundo uma determinada concepção de vida, e dos meios (processos e técnica) mais eficientes para efetivar estes ideais; 4. Profissão ou prática de ensinar. (AURÉLIO, 2004, p. 617). 
Pimenta (1995) nos mostra a Pedagogia em três Tendências, a primeira é a Pedagogia Liberal Tradicional que "define que a função da escola é a de preparar os indivíduos para o desempenho de papéis sociais previamente definidos, numa sociedade dada e não questionada, a partir das características individuais. A função da escola é a adaptação." (PIMENTA, 1995, p.126).

A segunda, como Pedagogia Tecnicista, "enfatiza esquemas de planejamento dentre os quais sistêmicas, valorizando a organização e a divisão racional do trabalho no interior da escola, como fatores de melhoria da qualidade do sistema." (PIMENTA, 1995, p.135).

E por fim a Pedagogia Crítico-Social dos Conteúdos que

[...] possibilita à escola buscar no seu interior respostas pedagógico-didáticas, articuladas à crítica dos mecanismos e imposições resultantes da sociedade organizada em classes sociais antagônicas. [...] a escola precisa de uma Pedagogia que a ajude a cumprir sua função específica que é transmitir o conhecimento de forma que os alunos dele se apropriem. (PIMENTA, 1995, p.140).

A Pedagogia Liberal Tradicional surgiu no final do século XIX, os procedimentos escolares era não-democráticos, o professor era a autoridade, não existia relação com o aluno, as avaliações eram apenas para verificação da quantidade de conhecimentos, e também visava apenas à memorização. A Pedagogia Tecnicista formava seu aluno para ser técnico, o que importava era a produção. Apesar de criticar a Pedagogia Tradicional, não alterava em nada o caráter seletivo da escola, melhora os meios de transmissão de conhecimento, mas não se interessa em conhecer a realidade dos alunos. Na Pedagogia Crítico-Social dos Conteúdos, luta-se por uma escola democrática, inicia seu trabalho a partir da realidade do aluno, permitindo-lhe tornar um ser crítico, capaz de ter uma visão ampla do que acontece ao seu redor.

Franco (2008) define a "Pedagogia como a ciência que estuda, compreende, esclarece, transforma e orienta a práxis educativa". Para ela:

Uma ciência pedagógica que em seu fazer social, assuma-se como instrumento político de emancipação dos homens, na direção de reorganizar condições de maior dignidade e igualdade entre os homens. A Pedagogia, na qualidade de ciência, há que ser formativa, de modo a poder ser emancipatória. (FRANCO, 2008, p. $70)$.

Já Libâneo (2000, p. 22) define que a "Pedagogia é o campo de conhecimento que se ocupa do estudo sistemático da educação, isto é, do ato educativo, da prática educativa concreta que se realiza na sociedade como um dos ingredientes básicos da configuração da atividade humana".

Por meio dessas definições sobre a Pedagogia, compreendemos que ela se modifica de acordo com as mudanças que ocorrem na educação. Entendemos também, que os teóricos aqui citados se referem à Pedagogia, principalmente, como a reflexão da práxis pedagógica, ela não é apenas o "saber" ensinar, mas uma reflexão da teoria e prática da educação.

Libâneo e Garrido (1999) são a favor de um curso específico de Pedagogia, pois

[...] trata-se de curso para a realização da investigação em estudos pedagógicos, tomando a pedagogia como campo teórico e como campo de atuação profissional. Como campo teórico, destina-se à formação de profissionais que desejem aprimorar a reflexão e a pesquisa sobre a educação e o ensino da pedagogia, propriamente dita. Como campo de atuação profissional, destina-se à preparação de pesquisadores, planejadores, especialistas em avaliação, gestores do sistema e da escola, 
coordenadores pedagógicos ou de ensino, comunicadores especializados para atividades escolares e extra-escolares, animadores culturais, de especialistas em educação a distância, de educadores de adultos no campo da formação continuada etc. (LIBÂNEO e GARRIDO, 1999, p. 8).

\title{
Esses autores ainda defendem a
}

[...] criação do curso de pedagogia, um curso que oferece formação teórica, científica e técnica para interessados no aprofundamento da teoria e da pesquisa pedagógica e no exercício de atividades pedagógicas específicas (planejamento de políticas educacionais, gestão do sistema de ensino e das escolas, assistência pedagógico-didática a professores e alunos, avaliação educacional, pedagogia empresarial, animação cultural, produção e comunicação nas mídias etc.). (LIBÂNEO e GARRIDO, 1999, p.8).

Concordamos com Libâneo (2000) quando afirma que a Pedagogia ocupa-se, de fato, dos processos educativos, métodos, maneiras de ensinar, mas antes disso, ela tem um significado bem mais amplo, bem mais globalizado. Ela é um campo de conhecimento sobre a problemática educativa na sua totalidade e historicidade e, ao mesmo tempo, uma diretriz orientadora da ação educativa. Essa ação educativa é de interesses sociais em conflitos na sociedade.

A educação ocorre em todo o lugar, na rua, na família, nos meios de comunicação, o que torna o campo educativo bastante vasto. A LDB 9394/96 no Art. $1^{\text {o }}$ confirma que os processos formativos se desenvolvem além das instituições de ensino. Assim sendo, Libâneo (2000) distingue diferentes manifestações e modalidades de prática educativa:

Educação Informal - corresponderia a ações e influência exercidas pelo meio, pelo
ambiente sociocultural, e que se desenvolve por meio das relações dos indivíduos e
grupos com seu ambiente humano; social; ecológico; físico e cultural, das quais
resultam conhecimentos, experiências, práticas, mas que não estão ligadas
especificamente a uma instituição nem são intencionais e organizadas. Educação
Não-Formal - é realizada em instituições educativas fora dos marcos institucionais,
mas com certo grau de sistematização e estruturação. Educação Formal -
compreenderia estâncias de formação, escolares ou não, onde há objetivos
educativos explícitos e uma aça intencional institucionalizada, estruturada,
sistemática. (LIBÂNEO, 2000, p.23)

Como a educação se desenvolve em vários âmbitos de uma sociedade, o meu objeto de pesquisa terá mais ênfase na Educação Não-Formal. A Educação pode dar-se de forma intencional e não-intencional. Para Fireman,

\begin{abstract}
A Educação não-intencional é aquela que acontece através da convivência social, do trabalho, das relações familiares e são adquiridas independentemente da vontade do sujeito. A intencional, que pode ser Formal e Não-Formal, ocorre através dos sindicatos, dos cursos de aperfeiçoamento, atividades escalares e extra-classe, ou seja, ela pode ter um objetivo previamente estabelecido e uma sistematização de conteúdos ou não. (FIREMAN, 2006, p. 52).
\end{abstract}

Gadotti (2005) deixa claro que a Educação Não-Formal não é definida por uma ausência da escola na vida do indivíduo, mas ultrapassa o limite do ensino escolar formal e engloba as experiências de vida e os processos de aprendizagem que são desenvolvidas no trabalho, na rua, na igreja, nas praças, enfim, em toda sociedade. Para ele, 
Toda educação é, de certa forma, educação formal, no sentido de ser intencional, mas o cenário pode ser diferente: o espaço da escola é marcado pela formalidade, pela regularidade, pela seqüencialidade. $\mathrm{O}$ espaço da cidade (apenas para definir um cenário da educação não-formal) é marcado pela descontinuidade, pela eventualidade, pela informalidade. A educação não-formal é também uma atividade educacional organizada e sistemática, mas levada a efeito fora do sistema formal. Daí também alguns a chamarem impropriamente de "educação informal". São múltiplos os espaços da educação não-formal. Além das próprias escolas (onde pode ser oferecida educação não-formal) temos as Organizações Não-Governamentais (também definidas em oposição ao governamental), as igrejas, os sindicatos, os partidos, a mídia, as associações de bairros, etc. Na educação não-formal, a categoria espaço é tão importante como a categoria tempo. O tempo da aprendizagem na educação não-formal é flexível, respeitando as diferenças e as capacidades de cada um, de cada uma. Uma das características da educação não-formal é sua flexibilidade tanto em relação ao tempo quanto em relação à criação e recriação dos seus múltiplos espaços. (GADOTTI, 2005, p. 2).

Com o crescimento do capitalismo, as mudanças da economia, o aparecimento de novas tecnologias, fizeram com que a Pedagogia tomasse um rumo diferente, percebeu-se, assim, que a educação está em diversas partes da sociedade. Essas transformações criaram novos sistemas de organização de trabalho, mudanças no perfil profissional e novas exigências de qualificação dos trabalhadores, que acabam afetando os sistemas de ensino. Segundo Franco (2008),

\begin{abstract}
A Pedagogia deve ter como um dos focos essenciais de seu trabalho o fazer educacional não só das escolas e de seus professores, mas das escolas e de seus professores, mas das diversas instituições com possibilidades educativas. Deve organizar-se na perspectiva de uma ação científica, essencialmente educativa, numa relação de humanização, orientação, leitura das diferentes práticas educacionais, ao mesmo tempo em que organiza espaços e condições pra que tais práticas possam ir se transformando e se adequando às novas condições que vão sendo construídas. (FRANCO, 2008, p.79).
\end{abstract}

\title{
3. A PERSPECTIVA DE ATUAÇÃO DO PEDAGOGO
}

O conhecimento é o grande capital da humanidade. Ele é básico para a sobrevivência e deve ser disponibilizado a todos. Espera-se que a Educação seja mais democrática e menos excludente. Desde a sua criação, a característica básica do curso de Pedagogia é a formação de seus profissionais para atuarem na escola como docentes, mas não podemos esquecer que a educação se dá em todos os lugares. É claro, que é de suma importância a formação de pedagogos docentes, pois assim, ele saberá articular com competência o trabalho na educação básica. As Diretrizes Curriculares Nacionais de 15 de maio de 2006 no Art. $2^{\circ}$ e $4^{\circ}$ deixa clara a responsabilidade da intervenção do pedagogo em quaisquer áreas que estejam previstos conhecimentos pedagógicos.

Assim sendo, o curso de Pedagogia terá que transmitir conceitos que vão além da sua função primordial que é a docência, mas como já sabemos o significado de Pedagogia, entendemos que o pedagogo é um investigador e também um profissional reflexivo sobre a práxis pedagógica. É importante que o curso de Pedagogia conscientize seus discentes sobre como um pedagogo realmente deve agir. Franco (2008) nos explica que

O pedagogo deverá ser o profissional investigador da educação como prática social.

Como investigador, pesquisará novas mediações da educação com o mundo

\begin{tabular}{|l|l|l|l|l|l|}
\hline Interfaces da Educ. & Paranaíba & v. 2 & n. 5 & p.99-109 & 2011 \\
\hline
\end{tabular}


sociocultural, além da escola, transcendendo o previsto nas demandas de mercado. Poderá investigar e criar meios de dialogar e produzir novas mediações com o mercado editorial, com meios de comunicação, com as novas organizações nãogovernamentais, com as instituições sociais já existentes, visando criar novos espaços educativos na sociedade, por meio da prática cientifica pedagógica. (FRANCO, 2008, p.112).

A sociedade e a educação, por muitos séculos, conduziam as pessoas a caminhos a serem seguidos. O trabalho era setorizado e fragmentado, as pessoas trabalhavam isoladamente, sob a pressão de apenas produzirem mais e mais. Como consequência disso, passaram a agir de forma mecânica, sem criatividade, não solucionavam problemas, acomodaram-se, não existia uma reflexão crítica e se aceitava tudo que era imposto.

O trabalho do pedagogo tem como característica o diagnóstico, a identificação de necessidades no processo ensino/aprendizagem, a indicação de metodologias adequadas, planejamento, acompanhamento e avaliação da ação educativa, para que tenha coerência com o ambiente em que atuará no mercado econômico e profissional. Nesse sentido, de acordo com Fireman (2006),

Ele pode atuar como formador, animador, instrutor, organizador, técnico, consultor e orientador de atividades pedagógicas não-escolares, e ainda como formadores ocasionais que estão ligados à atividade de transmissão de saberes e técnicas e outras atividades especializadas. (FIREMAN, 2006, p.66).

A ação educativa em ambientes não-escolares faz a diferença, a necessidade de se manter no emprego, desenvolver habilidades, competências e evoluir em sua carreira mostra a importância da formação de seus profissionais, e claro sem esquecer que com profissionais preparados, a empresa manterá seu status no mercado. Frison (2006) nos mostra que:

No Brasil, já é notória a presença de pedagogos nos espaços não-escolares. Isto se deve ao fato de as pessoas estarem sendo desafiadas a encontrar novas formas de atuação, a inovarem, a modificarem a organização de ambientes e de espaços de trabalho. Elas são desafiadas a implementar e dinamizar estratégias de ação que possibilitem um trabalho mais efetivo e gratificante. (FRISON, 2006, p.13).

Com a modernização e o crescimento do capitalismo, exigi-se um profissional que esteja em constante formação, que seja atualizado, que tenha a capacidade de acompanhar as evoluções que vão ocorrendo. Daí surge a necessidade de um pedagogo que faça um trabalho educativo, pois mais do que nunca, ele está capacitado com saberes que auxilie na evolução profissional.

Por isso, Fireman (2006) nos deixa claro que

[...] o pedagogo pode atuar em todas as áreas que requerem um trabalho educativo. Mas para atuar nesse novo contexto de sociedade, não basta ser formado em Pedagogia, é necessário buscar outros conhecimentos que dêem condições de desenvolver seu trabalho em qualquer instância da sociedade. Isso se faz necessário pelo fato de que o contingente dos pedagogos para o mercado de trabalho é originário de cursos em que a base curricular é a formação docente e atividades para a instituição escolar ou sistema escolar. (FIREMAN, 2006 p. 59-60).

O campo de atividade da educação não-formal é extenso, já podemos encontrar o pedagogo atuando na saúde: atua com planejamento e execução de programas de orientação e educação preventiva que envolve mídia falada e escrita, hospitais em acompanhamento em

\begin{tabular}{|l|l|l|l|l|l|}
\hline Interfaces da Educ. & Paranaíba & v. 2 & n. 5 & p.99-109 & 2011 \\
\hline
\end{tabular}


reforço escolar, atividades lúdicas. Nas empresas, atua com desenvolvimento e coordenação de projetos educacionais voltados para divulgação de produtos, produção e comunicação na mídia, pesquisa e análise e seleção de cursos e projetos a serem adotados pela empresa, orientação de funcionários para os cursos ministrados, organização de atividades dos estágios profissionais. Nos sindicatos, atua com planejamento, coordenação e execução de projetos de educação formal, qualificação e requalificação na perspectiva de empregabilidade dos seus associados no mercado de trabalho. No turismo, desenvolve atividades educativas (em conjunto com guias turísticos) que visem o conhecimento das localidades, sua história e cultura, consciência da preservação ecológica. Em museus, desenvolve estratégias educativas que proporcionem aos visitantes compreender a importância da memória cultural e sua relação com a atualidade; entre outros, o pedagogo realiza um trabalho multidisciplinar. Nesse sentido, para Gadotti (2000),

[...]a sociedade civil (ONGs, associações, sindicatos, igrejas, etc.) está se fortalecendo não apenas como espaço de trabalho, em muitos casos, voluntário, mas também como espaço de difusão de conhecimentos e de formação continuada. É um espaço potencializado pelas novas tecnologias, inovando constantemente nas metodologias. Novas oportunidades parecem abrir-se para os educadores. Esses espaços de formação têm tudo para permitir maior democratização da informação e do conhecimento, portanto, menos distorção e menos manipulação, menos controle e mais liberdade. É uma questão de tempo, de políticas públicas adequadas e de iniciativa da sociedade. A tecnologia não basta. É preciso a participação mais intensa e organizada da sociedade. $\mathrm{O}$ acesso à informação não é apenas um direito. É um direito fundamental, um direito primário, o primeiro de todos os direitos, pois sem ele não se tem acesso aos outros direitos. (GADOTTI, 2000, p. 5).

Fireman (2006), ao desenvolver sua Dissertação de Mestrado, com o tema "Trabalho do Pedagogo na Instituição Não-Escolar", pesquisou um pequeno número de pedagogos que atuam em diferentes instituições, desenvolvendo diversas e diferentes funções. Os pedagogos envolvidos desenvolvem atividades como: capacitação de professores para a Educação de Jovens e Adultos; planejamento educacional; acompanhamento do processo de aprendizagem de crianças em situação de risco; planejamento educacional para formação do cidadão; conscientização da comunidade; da capacitação de gestores educacionais para continuarem com programas de educação do cidadão; desenvolvimento de atividades de coordenação e em recursos humanos.

Para Frison (2006),

O estímulo ao desenvolvimento de competências e habilidades oportuniza aos trabalhadores momentos de integração nos quais aprendem a se relacionar, a conviver, a desenvolver a capacidade de análise e de crítica. Na convivência, as pessoas aprendem umas com as outras, especialmente ao participarem de propostas formativas que tenham como foco a aprendizagem. (FRISON, 2006, p. 17.)

Os pedagogos que foram pesquisados atuam na Educação Não-Formal de três meses a oito anos. Os tipos de atividades desenvolvidos nesse campo envolvem planejamento educacional, porém fora da escola. Para desenvolver algumas atividades, a dificuldade encontrada por esses pedagogos são nas questões como orçamento, quando o planejamento tinha como objetivo a comunicação por meio da propaganda veiculada na mídia. Outra coisa interessante que ela constata é que o conhecimento e experiências adquiridos na graduação não deram suporte para a superação dessas dificuldades, deixou claro que durante a prática ficou evidente a carência de mais conhecimentos, e que a teoria não foi o suficiente para 
ampará-los nas diversas atividades Não-Formais, o que os levou a buscarem, por meio de leituras e pesquisas, conhecimentos que os ajudassem a desenvolver com mais segurança suas atividades.

Ao elaborar, coordenar e avaliar projetos educacionais é necessário que esse profissional esteja inteirado da realidade sociocultural e econômico do campo onde se dará o processo educativo. O que caracteriza a presença do pedagogo nesses contextos é a conscientização de que com a globalização e o mercado competitivo, os sujeitos precisam estar em aprendizado contínuo. No momento, o mercado de trabalho não está preocupado apenas com a capacidade física do trabalhador, mas com sua capacidade intelectual. Isso requer do trabalhador uma maior habilidade para o trabalho em equipe, conhecimentos, criatividade e capacidade para solucionar problemas.

Fireman (2006) ouviu também algumas instituições e para sua surpresa, percebeu que existe certo desconhecimento do trabalho do pedagogo fora da escola. Alguns órgãos públicos só tinham pedagogo para obtenção de verbas.

\section{CONSIDERAÇÕES FINAIS}

De acordo com Libâneo (2000),

[...] o curso de Pedagogia deve formar o pedagogo "stricto sensu", isto é, um profissional qualificado para atuar em vários campos educativos para atender demandas sócio-educativas de tipo formal, não-formal e informal, decorrentes de novas realidades - novas tecnologias, novos atores sociais, ampliação das formas de lazer, mudanças nos ritmos de vida, presença dos meios de comunicação e informação, mudanças profissionais, desenvolvimento sustentado, preservação ambiental - não apenas na gestão, supervisão e coordenação pedagógica de escolas, como também na pesquisa, na administração dos sistemas de ensino, no planejamento educacional, na definição de políticas educacionais, nos movimentos sociais, nas empresa, nas várias instâncias de educação de adultos, nos serviços de psicopedagogia e orientação educacional, nos programas sociais, nos serviços para a terceira idade, nos serviços de lazer e animação cultural, na televisão, no rádio, na produção de vídeos, filmes, brinquedos, nas editoras, na requalificação profissional etc. (LIBÂNEO, 2000 p. 31).

Nesse sentido, estamos de acordo com Libâneo sobre a formação do pedagogo, pois a Educação está em plena transformação, e para isso é necessário que haja profissionais que acompanhem esse desenvolvimento. O leque de oportunidades para atuação do pedagogo é grande, só que pouco divulgado, cabe o curso de Pedagogia mostrar a importância de um profissional pesquisador.

Para o crescimento de uma sociedade instruída, a participação do pedagogo é fundamental, os trabalhos educativos realizados por esses profissionais na Educação NãoFormal formarão profissionais preparados para enfrentar a modernização. Segundo Frison (2006),

As possibilidades de exercício profissional do pedagogo são amplas, uma vez que o objeto principal do seu trabalho é o ato educativo, a aprendizagem humana. Aprender significa tomar conhecimento, tornar-se apto ou capaz de fazer alguma coisa, em conseqüência de estudo, observação, experiência. Projetos que estimulem aprendizagens são cada vez mais requisitadas nos locais de trabalho e podem representar uma mudança radical nas organizações e nas relações que nela acontecem. (FRISON 2006 p. 37-38). 
As ações educativas que são feitas na educação não-formal, não podem ser realizadas de qualquer forma, pois "todo trabalho docente é trabalho pedagógico, mas nem todo trabalho pedagógico é trabalho docente" (LIBÂNEO, 2000 p.31). Essa ótica nos mostra a contradição da finalidade do trabalho pedagógico, pois ele vai além da docência, intervindo em qualquer espaço onde a Educação alcança. Assim, a Educação Não-Formal abre oportunidades para os pedagogos atuarem. Para Fireman (2006),

As organizações empregadoras - empresas privadas, estatais, agências governamentais e instituições sem fins lucrativos - também precisam se transformar em instituições de aprendizado e de ensino. Esse é o desafio de todas as empresas e do sistema educacional seja na modalidade formal ou não-formal. (FIREMAN, 2006. p. 50).

Fireman (2006) nos mostra que a educação não é centralizada em um único ambiente, e hoje se torna um desafio para que as empresas mantenham o seu desenvolvimento e seus profissionais se efetivem no mercado de trabalho. Porém, não basta apenas saber ler e escrever, a rapidez das transformações tecnológicas e o mercado econômico, tornam o mercado de trabalho mais exigente.

Entretanto, sabemos que formar trabalhadores e desenvolver competências não é uma tarefa fácil, a educação é um processo que, segundo Libâneo (2000,)

Corresponde à ação educadora, às condições e modos pelos quais os sujeitos incorporam meios de se educar. Admitindo-se que toda educação implica uma relação de influências entre seres humanos, a educação-processo indica a atividade formativa nas várias instâncias com vistas a alcançar propósitos explícitos, intencionais, visando promover aprendizagens mediante a atividade própria dos sujeitos. (LIBÂNEO, 2000, P. 76).

Cabe ao mercado profissional e econômico ter a consciência de investir na educação, escolhendo um profissional qualificado com habilidades pedagógicas, capaz de enfrentar os desafios da modernização. O pedagogo faz reflexão sobre sua prática pedagógica, ele está em constante aprendizagem, por isso está preparado para atuar nos espaços não-escolares.

Entendemos que a ênfase no curso de Pedagogia é a formação docente, mas não podemos esquecer que a educação se dá em toda sociedade. Por isso o curso de Pedagogia deve também preparar os seus profissionais para enfrentar um mercado de trabalho fora dos ambientes escolares, que criem profissionais com competências para planejar, tomar decisões sobre o processo ensino-aprendizagem, e que possam estar capacitados para desenvolverem atividades educativas nas realidades mais diversificadas. "A base da identidade profissional do educador é a ação pedagógica, não a ação docente”. (LIBÂNEO, 2000, p. 47).

Para Frison (2006)

Nos espaços não-escolares, um dos desafios que se impõe ao pedagogo é desenvolver projetos voltados para o desenvolvimento de capacidades, de competências e de técnicas que tenham como ênfase a formação e a atualização dos sujeitos. O bom aproveitamento das estratégias de aprendizagem requer um sistema de auto-regulação fundamentado na reflexão crítica, na tomada de decisão, a partir do diálogo consigo mesmo e com a realidade. Nesta perspectiva, o pedagogo trabalha com o desenvolvimento de competências técnicas capazes de (re)orientar e potencializar a ação dos sujeitos. Esta ação implica participação do sujeito que é provocado a pensar sobre sua aprendizagem, que tem consciência de si mesmo e das necessidades do mundo que o rodeia. É importante desenvolver estratégias para sinalizar a necessidade de atualização constante. (FRISON, 2006, p. 25). 
Não se pode fugir da realidade, as mudanças que foram produzidas pela globalização causaram um grande impacto ao sistema educacional e na formação de seus profissionais. Portanto, a possibilidade de intervenção profissional para o pedagogo compreende uma ação educativa contribuindo para as relações sociais, influenciando conceitos, princípios, valores éticos que abrange todos os espaços do processo educativo. Acreditamos ser ele o profissional com conhecimentos específicos, que auxilia na melhor compreensão dos processos de ensinoaprendizado.

\section{REFERÊNCIAS}

LIBÂNEO, J. C. Pedagogia e Pedagogos, Para Quê? 3. ed. São Paulo: Cortez, 2000.

FRANCO, M. A. Santoro. Pedagogia Como Ciência da Educação. 2. ed. São Paulo: Cortez, 2008.

FIREMAN, M. D. O Trabalho do Pedagogo na Instituição Não-Escolar. 2006. Dissertação (Mestrado em Educação) - Universidade Federal de alagoas, Maceió, 2006.

FRISON, L. M. B. Auto-Regulação da Aprendizagem: Atuação do Pedagogo em Espaços Não-Escolares. Tese (Doutorado em Educação) Pontifícia Universidade Católica do Rio Grande do Sul, Porto Alegre, 2006.

GADOTTI, M. Perspectiva Atuais da Educação. Porto Alegre:Ed. Artes Médica, 2000. . A Questão da Educação Formal / Não-Formal. Institut International Des Droits de L'Enfant (IDE). Suiça, 2005: artigo

LIBÂNEO, J. C. e PIMENTA, S. G. Formação de Profissionais da Educação: Visão Crítica e Perspectiva de Mudança. Educação e Sociedade. V. 20, n.68, Campinas, 1999.

LIMA, E. F. Formação de Professores: Passado, Presente e Futuro: O Curso de Pedagogia. In MACIEL, Lizete Shizue Bomura; SHIGUNOV NETO, Alexandre (Org.). Formação de Professores: Passado, Presente e Futuro. São Paulo, Cortez, 2004.

PIMENTA, S. G. O Pedagogo na Escola Pública. 3. ed. São Paulo, Loyola, 1995. 